\title{
Synthesis of IFN- $\beta$ by Virus-Infected Chicken Embryo Cells Demonstrated with Specific Antisera and a New Bioassay
}

\author{
HEIKE SCHWARZ, ${ }^{1, *}$ OLOF HARLIN, ${ }^{2, *}$ ANNETTE OHNEMUS, ${ }^{1}$ BERND KASPERS, ${ }^{2}$ \\ and PETER STAEHELI ${ }^{1}$
}

\begin{abstract}
Transcripts of interferon- $\alpha$ (IFN- $\alpha$ ) and IFN- $\beta$ genes are present in virus-infected chicken cells, but because of a lack of appropriate assays and reagents, it was unclear if biologically active IFN- $\beta$ is secreted. We have established a nonviral bioassay for the sensitive detection of chicken IFN (ChIFN). This assay is based on a quail cell line that carries a luciferase gene that is controlled by the IFN-responsive chicken Mx promoter. Luciferase activity was strongly stimulated when the indicator cells were incubated with ChIFN- $\alpha$, ChIFN$\beta$, or ChIFN- $\gamma$ but not with chicken interleukin-1 $\beta$ (ChIL-1 $\beta$ ). Unlike the classic antiviral assay that preferentially detects ChIFN- $\alpha$, the Mx-luciferase assay detected ChIFN- $\alpha$ and ChIFN- $\beta$ with similar sensitivity. With the help of this novel assay and with rabbit antisera specific for either IFN- $\alpha$ or IFN- $\beta$, we analyzed the composition of IFN in supernatants of virus-infected chicken embryo cells. Virtually all IFN produced in response to Newcastle disease virus (NDV) was IFN- $\alpha$. However, IFN produced in response to influenza A or vaccinia virus $(\mathrm{VV})$ was a mixture of usually more than $80 \%$ IFN- $\alpha$ and up to $20 \%$ IFN- $\beta$. Thus, IFN- $\alpha$ and IFN- $\beta$ both contribute to the cytokine activity in supernatants of virus-infected chicken cells. Furthermore, the infecting virus appears to determine the IFN subtype composition.
\end{abstract}

\section{INTRODUCTION}

$\mathbf{T}$ The FIRST CDNA For VIRUS-INDUCEd chicken interferon (ChIFN) was cloned in 1994. ${ }^{(1)}$ Subsequent work revealed that the chicken uses at least 10 intronless genes to provide IFN$\alpha .^{(2)}$ Low-stringency hybridization screening of a phage library resulted in identification of a distantly related intronless ChIFN gene, ${ }^{(2)}$ now designated IFN- $\beta .^{(3)}$ The IFN- $\alpha$ and IFN- $\beta$ genes are clustered and map to the tip of the long arm of the chicken $\mathrm{Z}$ chromosome. ${ }^{(4)}$ Because polyclonal antisera raised against recombinant IFN- $\alpha$ failed to neutralize the antiviral activity of IFN- $\beta{ }^{(2)}$ it was concluded that chickens, like mammals, possess serologically distinct type I IFNs. However, it remained unclear if IFN- $\beta$ contributes to the antiviral state in chickens because an IFN- $\alpha$-specific antiserum almost completely neutralized the antiviral activity secreted by either chicken spleen cells in response to concanavalin A (ConA $)^{(5)}$ or chicken embryo cells in response to DNA transfection. ${ }^{(6)}$ Furthermore, birds injected with monoclonal antibody (mAb) 8A9, which specifically neutralizes ChIFN- $\alpha$, showed enhanced tumor incidence in Rous sarcoma virus-infected chickens. ${ }^{(7)}$ As work with recombinant chicken cytokines indicated that the specific antiviral activity of IFN- $\beta$ was approximately 10 -fold lower than that of IFN- $\alpha,{ }^{(2)}$ it remained unclear whether the magnitude of ChIFN- $\beta$ synthesis had been underestimated previously.

Recent research interest focuses on the question of why many viruses manage to replicate surprisingly well in the face of a strong innate immune response of the infected hosts. ${ }^{\left({ }^{8}\right)}$ Emerging evidence indicates that most successful viruses, including such pathogens of poultry as Newcastle disease virus (NDV) and influenza A virus, code for proteins that interfere with the IFN system. For example, the NS1 protein of influenza A virus limits IFN production in infected cells presumably by sequestering double-stranded RNA (dsRNA), ${ }^{(9)}$ which would otherwise trigger toll-like receptor-3 (TLR-3) activation and other innate immune responses. The V protein of NDV has a different mode of action against the host IFN response. It limits the action of IFN by blocking IFN-dependent signaling pathways. ${ }^{(10-12)}$ Pathogenesis studies of these viruses in avian hosts are hampered by incomplete knowledge of the ChIFN system and by a shortage of suitable reagents.

We have developed specific antisera to $\mathrm{ChIFN}-\alpha$ and

\footnotetext{
${ }^{1}$ Department of Virology, University of Freiburg, D-79104 Freiburg, Germany.

${ }^{2}$ Institute of Animal Physiology, University of Munich, D-80539 Munich, Germany.

${ }^{*}$ These two authors contributed equally to this work.
} 
ChIFN- $\beta$ and set up an alternative bioassay that detects IFN- $\beta$ with high sensitivity. Our experiments demonstrated that IFN$\alpha$ and IFN- $\beta$ can both be produced during infection of chicken embryo cells with viruses, such as influenza A virus.

\section{MATERIALS AND METHODS}

\section{Recombinant chicken cytokines}

Human 293T cells were transiently transfected with cDNA expression constructs (pcDNA vector) (Invitrogen, San Diego, CA) for ChIFN- $\alpha,{ }^{(2)} \mathrm{ChIFN}-\beta,{ }^{(2)} \mathrm{ChIFN}-\gamma,{ }^{(5,13)}$ and N-terminally truncated interleukin- $\beta$ (IL- $1 \beta$ ) (ATG-80-11-12(14) $)$. At 16-20 $\mathrm{h}$ after plasmid transfection, the medium was changed. Media containing the various cytokines were harvested $48 \mathrm{~h}$ later, and cell debris was removed by centrifugation. Short-term storage of the samples was at $4^{\circ} \mathrm{C}$, and long-term storage was at $-20^{\circ} \mathrm{C}$

\section{Virus-induced natural ChIFN}

Confluent monolayers of cells prepared from 10-day-old chicken embryos were infected with various viruses at a multiplicity of infection (moi) of 5. Viruses used in this study were NDV strain H53, ${ }^{(15)}$ influenza A virus PR8 lacking the NS1 gene (FluA), ${ }^{(9)}$ modified vaccinia virus (VV) Ankara (MVA), ${ }^{(16)}$ Rift valley fever virus strain $\mathrm{M} 19{ }^{(17)}$ and the Freiburg variant of Thogotovirus lacking the ability to synthesize the ML protein. ${ }^{(18)}$ At approximately 48 hours post infection, the culture media were harvested. The cell debris was removed by centrifugation, and the supernatants were treated with perchloric acid as described. ${ }^{(19)}$ At the end of the acid treatment procedure, the $\mathrm{pH}$ was brought back into the neutral range, the insoluble precipitate was removed by centrifugation, and the cleared supernatants were stored at $4^{\circ} \mathrm{C}$. Before use, the supernatants were incubated overnight at $4{ }^{\circ} \mathrm{C}$ with the indicated amounts of the various antisera.

\section{IFN assays}

Antiviral assay. Vesicular stomatitis virus (VSV) was used to challenge cytokine-treated CEC-32 quail cells as described. ${ }^{(16)}$

Nonviral assay. A plasmid in which luciferase gene expression is controlled by a short fragment (position -216 to +45 ) of the chicken Mx promoter ${ }^{(20)}$ was transfected into CEC-32 cells, and stably transfected cells were selected. These cells were seeded at approximately $2 \times 10^{5}$ cells per well into 24 well dishes. They were treated for $6 \mathrm{~h}$ with the indicated dilutions of the various cytokines. Subsequently, the culture medium was removed, and the cells were lysed in $100 \mu$ lysis buffer (Promega, Madison, WI). Samples of the lysate were used for measuring luciferase activity using a kit (Promega) as recommended by the manufacturer.

\section{Antisera}

The rabbit antiserum against $\mathrm{ChIFN}-\alpha$ has been described previously. ${ }^{(2,5)}$ The rabbit antiserum to ChIFN- $\beta$ was produced by repeated intramuscular (i.m.) injections of purified, bacteri- ally produced ChIFN- $\beta$ emulsified in Freund's complete (first immunization) or incomplete (subsequent immunizations) adjuvant. Both antisera were used individually at $0.5 \%$ or in combination at $0.5 \%$ each. Preimmune sera used at the same concentrations served as negative controls.

\section{RESULTS}

\section{An alternative bioassay for ChIFN}

IFN activity is traditionally determined with antiviral assays in which cytokine-treated cells are analyzed for acquired resistance to infection by a challenge virus. ${ }^{(21)}$ Alternative assays rely on the fact that biologically active IFN triggers a signaling cascade in susceptible cells that causes transcriptional activation of many genes, including $M x$. We, therefore, established a quail cell line that carries a luciferase reporter gene controlled by the IFN-stimulated response element (ISRE) of the chicken Mx promoter. ${ }^{(20)}$ The quail cell line CEC-32 was used because previous work demonstrated that it has favorable growth properties and that it responds to ChIFNs with high sensitivity. $(2,5)$ To determine if this indicator cell line would show the expected IFN response, we exposed the cells for $6 \mathrm{~h}$ to various recombinant chicken cytokines. Exposure to IFN- $\alpha$ and IFN- $\beta$ resulted in approximately 30-fold increased levels of luciferase activity compared with the untreated control (Fig. 1). IFN- $\gamma$ was also active in this assay, although the luciferase levels were enhanced only about 10 -fold. In contrast, treatment of the indicator cell line with a high dose of ChIL- $1 \beta$ did not cause significantly enhanced luciferase levels (Fig. 1).

Supernatants of human $293 \mathrm{~T}$ cells transiently transfected with expression plasmids for chicken ChIFN- $\alpha$ or ChIFN- $\beta$ remained active until diluted at least 1,000,000-fold (Fig. 2, left), indicating a very high sensitivity of the new bioassay. In repeated experiments, half-maximal luciferase values were obtained with recombinant ChIFN- $\alpha(\mathrm{rChIFN}-\alpha)$ that was diluted some 160,000 -fold and $\operatorname{rChIFN}-\beta$ that was diluted some

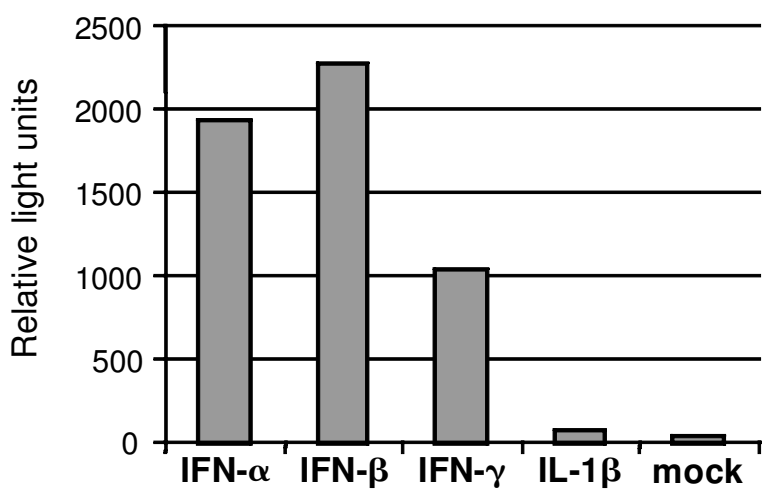

FIG. 1. IFN response of indicator cells carrying an Mx promoter-controlled luciferase reporter gene. The indicator cells were incubated for $6 \mathrm{~h}$ with 1000-fold diluted supernatants of transfected human $293 \mathrm{~T}$ cells expressing empty pcDNA1 (mock) or pcDNA1 vectors encoding either ChIFN- $\alpha$, ChIFN$\beta$, ChIFN- $\gamma$, or ChIL- $1 \beta$. 
LUC assay

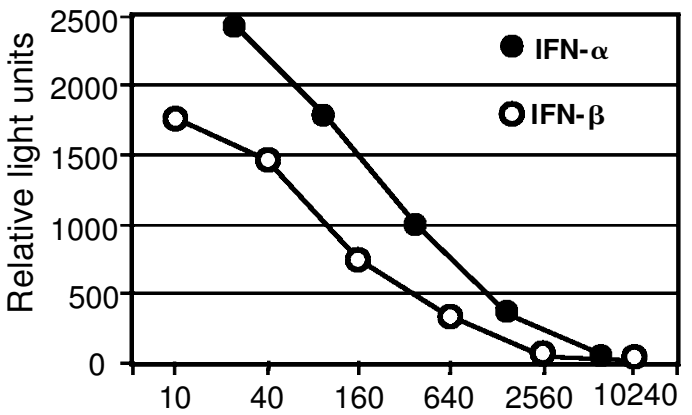

Dilution of 293T supernatants $(x 1000)$

\section{antiviral assay}

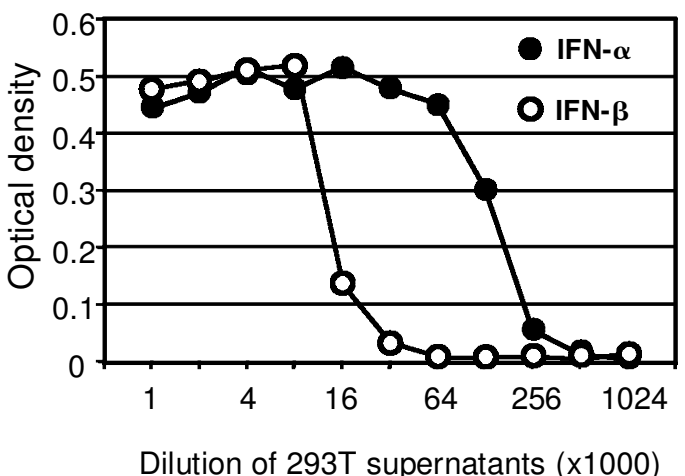

FIG. 2. The Mx-luciferase assay detects IFN- $\beta$ with higher sensitivity than the classic antiviral assay. End point titrations of rChIFN- $\alpha$ and rChIFN- $\beta$ from transfected 293 T cells were performed in the two alternative assays.

60,000 -fold. rIFN- $\gamma$ was far less active. Half-maximal luciferase values were measured with approximately 500 -fold diluted $293 \mathrm{~T}$ cell supernatant (data not shown). Classic antiviral assays (Fig. 2, right) demonstrated that the IFN- $\alpha$ preparation used had a titer of $160,000 \mathrm{U} / \mathrm{ml}$, whereas the titer of the IFN$\beta$ preparation was about $12,000 \mathrm{U} / \mathrm{ml}$. Thus, IFN- $\alpha$ was detected with comparable sensitivity by both assays, whereas
IFN- $\beta$ was detected about 5 -fold better by the Mx-luciferase assay.

\section{Antisera specifically neutralizing either ChIFN- $\alpha$} or ChIFN- $\beta$

We previously described a rabbit antiserum that efficiently neutralized ChIFN- $\alpha$ but not ChIFN- $\beta .^{(2)}$ By repeated immu-
A

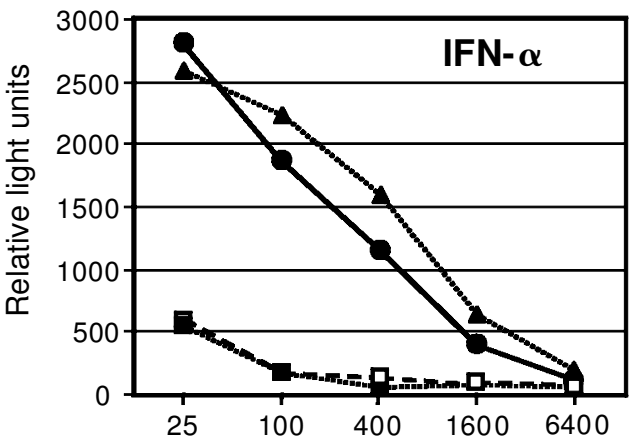

Dilution of 293T supernatants (x1000)

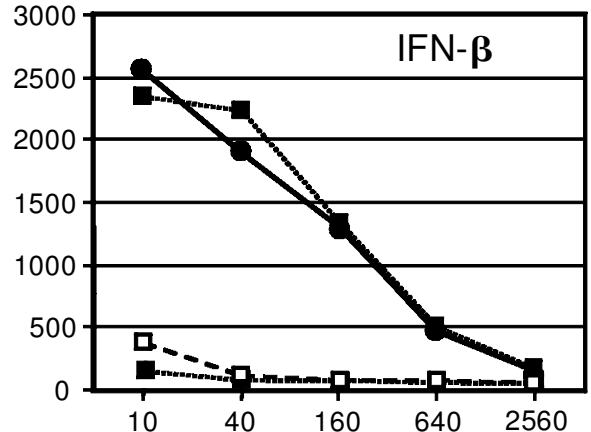

Dilution of 293T supernatants (x1000)
Control serum

Anti-IFN- $\alpha$ serum

$\Delta$ Anti-IFN- $\beta$ serum

口 Anti-IFN- $\alpha+$ anti-IFN- $\beta$
B

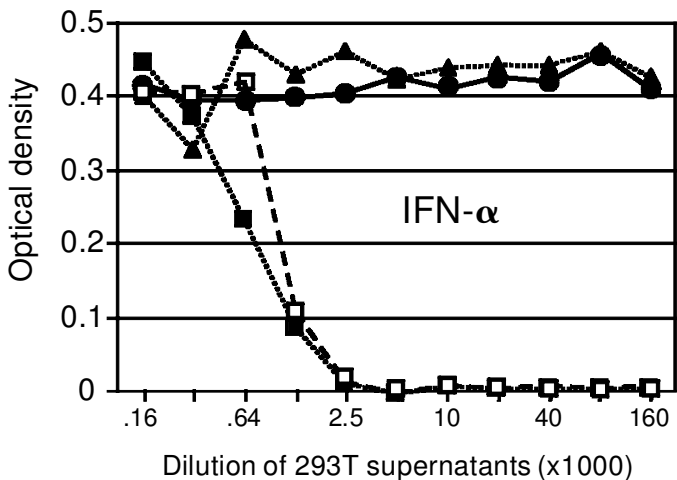

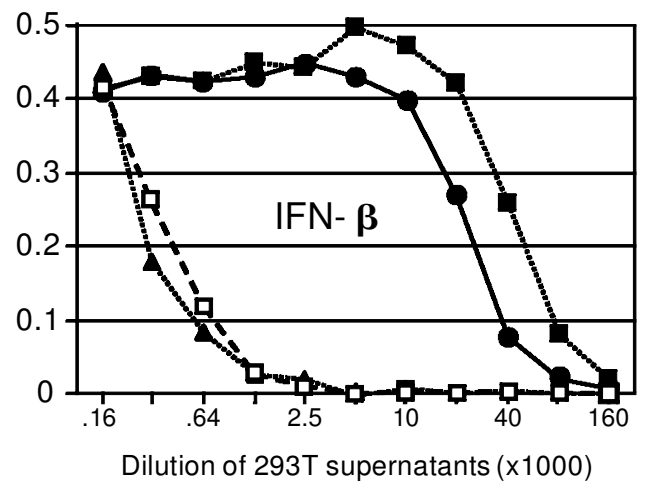

FIG. 3. Rabbit antisera exhibit a high degree of selectivity for $\operatorname{rIFN}-\alpha$ and rIFN- $\beta$ in the Mx-luciferase assay (A) and in the classic antiviral assay $(\mathbf{B})$. Antisera were used at $0.5 \%$ each. Control serum was used at $0.5 \%$. 
nization of a rabbit with purified $\operatorname{rChIFN}-\beta$, we also generated an antiserum with high specificity for IFN- $\beta$. When used at a final concentration of $0.5 \%$, the IFN- $\alpha$ antiserum reduced the activity of rChIFN- $\alpha$ from transfected human 293 T cells by about 60 -fold. The IFN- $\beta$ antiserum was similarly effective against $\mathrm{rChIFN}-\beta$ (Fig. 3). Importantly, the two antisera showed no measurable cross-reactivity; that is, each antiserum exhibited a very high degree of specificity for the corresponding IFN subtype (Fig. 3). Virtually identical datasets were obtained with the Mx-luciferase assay (Fig. 3A) and the antiviral assay (Fig. 3B).

\section{Natural ChIFN- $\beta$ in supernatants of virus-infected embryo cells}

Virus-infected chicken embryo cells are a good source of natural type I IFN. ${ }^{(19)}$ We, therefore, infected these cells with a panel of viruses and assayed the supernatants for IFN activity at $48-72 \mathrm{~h}$ postinfection. In order to destroy the inducing virus and to eliminate other activities that might interfere in the IFN assay, the supernatants were subjected to extensive perchloric acid treatment as described. ${ }^{(19)}$ High IFN activity was repeatedly measured in supernatants of cells infected with either NDV, FluA, MVA. In a typical experiment, such super- natants strongly activated the Mx-luciferase construct in our indicator cells if diluted less than approximately 1000-fold (Fig. $4)$. In the presence of a 1:1 mixture of IFN- $\alpha$-specific and IFN$\beta$-specific antisera, the IFN activity in the various supernatants was reduced some 60 -fold (Fig. 4), demonstrating that natural virus-induced ChIFN consists mainly of these two IFN subtypes. In the exclusive presence of antiserum to IFN- $\alpha$, the supernatant from NDV-induced cells lost all its activity (Fig. 4), indicating that almost no IFN- $\beta$ was present. In contrast, antiserum to IFN- $\alpha$ alone was rather ineffective on supernatants from cells infected with either influenza A virus or MVA. Inclusion of antiserum to IFN- $\alpha$ alone reduced the activity of these supernatants only about 4-8-fold compared with about 60 -fold if both antisera were present (Fig. 4). In the exclusive presence of antiserum to IFN- $\beta$, no significant changes in the IFN activity were recorded. These observations suggested that IFN- $\alpha$ was responsible for about $80 \%$ of the IFN activity in the supernatants of cells infected with influenza A virus or MVA. Furthermore, these data unambiguously demonstrated that a small fraction of the IFN activity ( $20 \%$ or less) was due to the presence of IFN- $\beta$.

Our results also illustrated clearly that detection of minor IFN subtypes in mixed IFN preparations can be very demanding. The difficulty stems from the fact that the bioassays can-
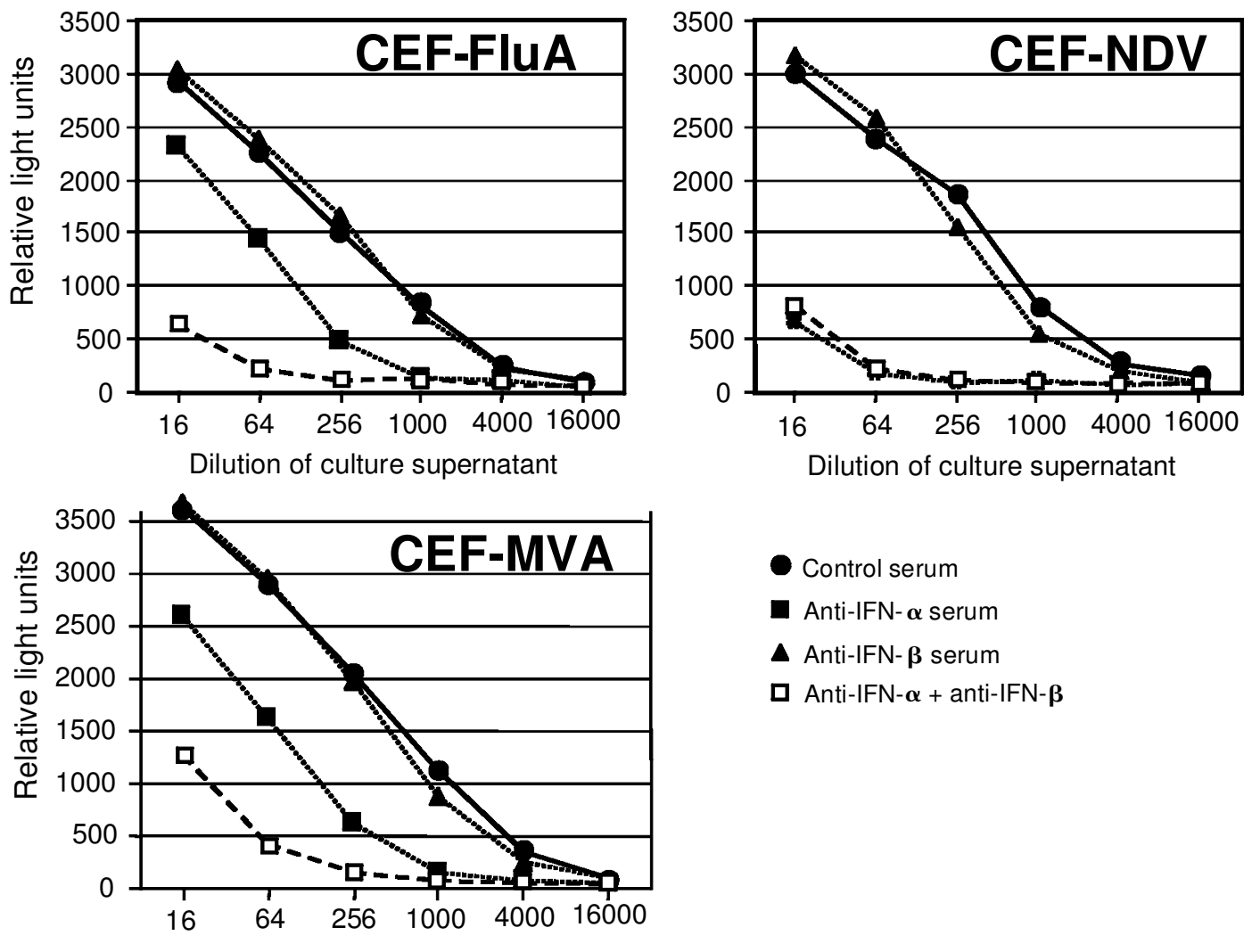

Control serum

Anti-IFN- $\boldsymbol{\alpha}$ serum

$\Delta$ Anti-IFN- $\boldsymbol{\beta}$ serum

口 Anti-IFN- $\boldsymbol{\alpha}+$ anti-IFN- $\boldsymbol{\beta}$

Dilution of culture supernatant

FIG. 4. Natural IFN in supernatants of virus-infected chicken embryo cells is a mixture of IFN- $\alpha$ and IFN- $\beta$. Confluent cell monolayers were infected with either FluA, NDV, MVA at an moi of 5. Forty-eight hours later, the supernatants were harvested and treated with acid to destroy virus. IFN composition and titers were determined with the Mx-luciferase assay using the specific antisera as in Figure 3. 
not distinguish between preparations with titer differences of less than 2-fold. Only after the dominant IFN species is neutralized does the activity of the other subtypes become readily detectable. We noted that overall synthesis of IFN and relative amount of IFN- $\beta$ produced in response to infection with influenza A virus and MVA varied considerably between experiments (data not shown). The reason for this variability is unknown at present. It may be related to the fact that primary chick embryo cells require proper aging in vitro before they respond to external stimuli with vigorous IFN synthesis. ${ }^{(19,22)}$

\section{DISCUSSION}

Although chickens possess genes for IFN- $\alpha$ and IFN- $\beta$, several previous observations suggested that IFN- $\beta$ may not contribute significantly to the antiviral defense of chickens. Using conventional IFN titration assays that measure the antiviral activity of the cytokine against VSV, the specific activity of rChIFN- $\beta$ was found to be about 10-fold lower than that of ChIFN- $\alpha .{ }^{(2)}$ Selective in vivo neutralization of IFN- $\alpha$ with an $\mathrm{mAb}$ resulted in enhanced tumor incidence in Rous sarcoma virus-infected chickens. ${ }^{(7)}$ Finally, the application of antisera to IFN- $\alpha$ alone abrogated plasmid DNA transfection-induced antiviral state of chicken embryo cells toward an IFN-sensitive NDV strain.(6) The experiments described in this report were performed to determine if IFN- $\beta$ is indeed produced under physiologic conditions. By using a nonviral IFN assay, we found that IFN- $\alpha$ and IFN- $\beta$ exhibit comparable specific activities, arguing against the possibility that the previously observed reduced antiviral activity of $\mathrm{rChIFN}-\beta$ resulted from technical problems associated with the production and purification of this cytokine. Direct evidence that biologically active IFN- $\beta$ is secreted by virus-infected chicken cells came from experiments in which antisera with high specificity for either IFN$\alpha$ or IFN- $\beta$ were used. These studies revealed that IFN- $\alpha$ is the dominant virus-induced IFN subtype of chicken embryo cells. They further showed that infection of these cells by some but clearly not all viruses also leads to secretion of detectable levels of IFN- $\beta$.

The new Mx-luciferase bioassay we used for measuring IFN activity has several advantages over the conventional antiviral assay. Unlike the antiviral assay, the Mx-luciferase assay detects IFN- $\alpha$ and IFN- $\beta$ with high sensitivity, it is very fast and can be completed in about $7 \mathrm{~h}$, and it works without infectious agents and can thus be performed in laboratories that lack a permit for work with potentially dangerous viruses. Like the conventional antiviral assay, the Mx-luciferase assay is not specific for type I IFN but responds to IFN- $\gamma$. This latter property was unexpected because the mammalian $M x$ genes are preferentially induced by IFN- $\alpha$ and IFN- $\beta$. It should be noted that our indicator cells carry a reporter gene that is controlled by an artificially truncated Mx promoter consisting of less than $250 \mathrm{nt}$ of regulatory sequence that contain positive acting elements but might lack some control elements that determine type I IFN specificity. It is also possible that the $M x$ genes of birds show an intrinsically less restricted response to the various IFN subtypes. The literature contains insufficient data on the regulation of the endogenous $M x$ gene of the chicken to distinguish between these possibilities.
The antisera we generated by repeated immunization of rabbits with bacterially produced either IFN- $\alpha$ or IFN- $\beta$ showed a very high degree of specificity for the corresponding IFN subtype. Thus, as in mammals, IFN- $\alpha$ and IFN- $\beta$ of the chicken are serologically distinct cytokines. This property confirms the validity of the recently introduced nomenclature of ChIFNs in which the nomenclature previously used for mammalian IFNs

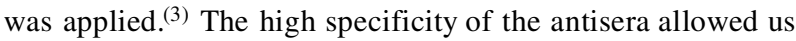
for the first time to perform a complete analysis of the IFN composition in the medium of virus-infected chicken cells. Our observation that IFN- $\alpha$ was predominantly present in these samples fits nicely with earlier reports that stressed the importance of IFN- $\alpha$ in the antiviral defense of the chicken. It is important to note, however, that the $\mathrm{VV}$ and the influenza A virus used in this study also induced good quantities of biologically active IFN- $\beta$, whereas NDV (Fig. 4), Thogoto virus, and Rift valley fever virus (unpublished observations) did not. This contrasts with the situation in mammals in which IFN- $\beta$ is the dominant type I IFN species produced by virus-infected cells. These subtle differences in gene regulation and the reduced specific antiviral activity toward VSV of chicken IFN- $\beta$ may be taken as preliminary evidence that IFN- $\alpha$ primarily serves the antiviral defense in chickens. A picture thus emerges in which ChIFN$\beta$ appears to primarily serve a different as yet undefined physiologic role, such as, for example, promoting the maturation of dendritic cells in response to viral infection. ${ }^{(23)}$

\section{ACKNOWLEDGMENTS}

This work was supported by a grant from the European Union.

\section{REFERENCES}

1. SEKELLICK, M.J., FERRANDINO, A.F., HOPKINS, D.A., and MARCUS, P.I. (1994). Chicken interferon gene: cloning, expression, and analysis. J. Interferon Res. 14, 71-79.

2. SICK, C., SCHULTZ, U., and STAEHELI, P. (1996). A family of genes coding for two serologically distinct chicken interferons. J. Biol. Chem. 271, 7635-7639.

3. LOWENTHAL, J.W., STAEHELI, P., SCHULTZ, U., SEKELLICK, M.J., and MARCUS, P.I. (2001). Nomenclature of avian interferon proteins. J. Interferon Cytokine Res. 21, 119-127.

4. NANDA, I., SICK, C., MUNSTER, U., KASPERS, B., SCHARTL, M., STAEHELI, P., and SCHMID, M. (1998). Sex chromosome linkage of chicken and duck type I interferon genes: further evidence of evolutionary conservation of the $\mathrm{Z}$ chromosome in birds. Chromosoma 107, 204-210.

5. WEINING, K.C., SCHULTZ, U., MUNSTER, U., KASPERS, B., and STAEHELI, P. (1996). Biological properties of recombinant chicken interferon-gamma. Eur. J. Immunol. 26, 2440-2447.

6. PARK, M.S., SHAW, M.L., MUNOZ-JORDAN, J., CROS, J.F., NAKAYA, T., BOUVIER, N., PALESE, P., GARCIA-SASTRE, A., and BASLER, C.F. (2003). Newcastle disease virus (NDV)based assay demonstrates interferon-antagonist activity for the NDV V protein and the Nipah virus $\mathrm{V}, \mathrm{W}$, and $\mathrm{C}$ proteins. J. Virol. 77, 1501-1511

7. PLACHY, J., WEINING, K.C., KREMMER, E., PUEHLER, F., HALA, K., KASPERS, B., STAEHELI, P. (1999). Protective effects of type I and type II interferons toward Rous sarcoma virusinduced tumors in chickens. Virology 256, 85-91. 
8. LEVY, D.E., and GARCIA-SASTRE, A. (2001). The virus battles: IFN induction of the antiviral state and mechanisms of viral evasion. Cytokine Growth Factor Rev. 12, 143-156.

9. GARCIA-SASTRE, A., EGOROV, A., MATASSOV, D., BRANDT, S., LEVY, D.E., DURBIN, J.E., PALESE, P., and MUSTER, T. (1998). Influenza A virus lacking the NS1 gene replicates in interferon-deficient systems. Virology 252, 324-330.

10. HUANG, Z., KRISHNAMURTHY, S., PANDA, A., and SAMAL, S.K. (2003). Newcastle disease virus V protein is associated with viral pathogenesis and functions as an alpha interferon antagonist. J. Virol. 77, 8676-8685.

11. PARK, M.S., GARCIA-SASTRE, A., CROS, J.F., BASLER, C.F., and PALESE, P. (2003). Newcastle disease virus V protein is a determinant of host range restriction. J. Virol. 77, 9522-9532.

12. MEBATSION, T., DE VAAN, L.T., DE HAAS, N., ROMEROBERDORFER, A., and BRABER, M. (2003). Identification of a mutation in editing of defective Newcastle disease virus recombinants that modulates P-gene mRNA editing and restores virus replication and pathogenicity in chicken embryos. J. Virol. 77, 9259-9265.

13. DIGBY, M.R., and LOWENTHAL, J.W. (1995). Cloning and expression of the chicken interferon-gamma gene. J. Interferon Cytokine Res. 15, 939-945.

14. GYORFY, Z., OHNEMUS, A., KASPERS, B., DUDA, E., and STAEHELI, P. (2003). Truncated chicken interleukin-1beta with increased biologic activity. J. Interferon Cytokine Res. 23, 223-228.

15. BAZZIGHER, L., PAVLOVIC, J., HALLER, O., and STAEHELI, P. (1992). $M x$ genes show weaker primary response to virus than other interferon-regulated genes. Virology 186, 154-160.

16. HORNEMANN, S., HARLIN, O., STAIB, C., KISLING, S., ERFLE, V., KASPERS, B., HACKER, G., and SUTTER, G. (2003). Replication of modified vaccinia virus Ankara in primary chicken embryo fibroblasts requires expression of the interferon resistance gene E3L. J. Virol. 77, 8394-8407.

17. BOULOY, M., JANZEN, C., VIALAT, P., KHUN, H., PAVLOVIC, J., HUERRE, M., and HALLER, O. (2001). Genetic evidence for an interferon-antagonistic function of Rift Valley fever virus nonstructural protein NSs. J. Virol. 75, 1371-1377.
18. HAGMAIER, K., JENNINGS, S., BUSE, J., WEBER, F., and KOCHS, G. (2003). Novel gene product of Thogoto virus segment 6 codes for an interferon antagonist. J. Virol 77, 2747-2752.

19. SEKELLICK, M.J., and MARCUS, P.I. (1986). Induction of high titer chicken interferon. Methods Enzymol. 119, 115-125.

20. SCHUMACHER, B., BERNASCONI, D., SCHULTZ, U., and STAEHELI, P. (1994). The chicken Mx promoter contains an ISRE motif and confers interferon inducibility to a reporter gene in chick and monkey cells. Virology 203, 144-148.

21. DE MAEYER, E.M., and DE MAEYER-GUIGNARD, J. (1988). Interferons and Other Regulatory Cytokines. New York: Wiley Interscience.

22. SEKELLICK, M.J., BIGGERS, W.J., and MARCUS, P.I. (1990). Development of the interferon system. I. In chicken cells development in ovo continues on time in vitro. In Vitro Cell Dev. Biol. 26, 997-1003.

23. HONDA, K., SAKAGUCHI, S., NAKAJIMA, C., WATANABE, A., YANAI, H., MATSUMOTO, M., OHTEKI, T., KAISHO, T., TAKAOKA, A., AKIRA, S., SEYA, T., and TANIGUCHI, T. (2003). Selective contribution of IFN- $\alpha / \beta$ signaling to the maturation of dendritic cells induced by double-stranded RNA or viral infection. Proc. Natl. Acad. Sci. USA 100, 10872-10877.

Address reprint requests or correspondence to: Dr. Peter Staeheli Department of Virology University of Freiburg Hermann-Herder-Strasse 11

D-79104 Freiburg Germany

Tel: $+49-761-203-6579$

Fax: +49-761-203-5350

E-mail: staeheli@ukl.uni-freiburg.de

Received 24 September 2003/Accepted 7 November 2003 


\section{This article has been cited by:}

1. Lonneke Vervelde, Sylvia S. Reemers, Daphne A. van Haarlem, Jacob Post, Erwin Claassen, Johanna M.J. Rebel, Christine A. Jansen. 2013. Chicken dendritic cells are susceptible to highly pathogenic avian influenza viruses which induce strong cytokine responses. Developmental \& Comparative Immunology 39:3, 198-206. [CrossRef]

2. L. Vervelde, M.G.R. Matthijs, D.A. van Haarlem, J.J. de Wit, C.A. Jansen. 2013. Rapid NK-cell activation in chicken after infection with infectious bronchitis virus M41. Veterinary Immunology and Immunopathology 151:3-4, 337-341. [CrossRef]

3. Christopher P. Malinoski, Philip I. Marcus. 2013. Influenza Virus Subpopulations: Interferon InductionSuppressing Particles Require Expression of NS1 and Act Globally in Cells; UV Irradiation of InterferonInducing Particles Blocks Global Shut-Off and Enhances Interferon Production. Journal of Interferon \& Cytokine Research 33:2, 72-79. [Abstract] [Full Text HTML] [Full Text PDF] [Full Text PDF with Links]

4. Adam J. Karpala, John W. Lowenthal, Andrew G.D. Bean. 2012. Identifying innate immune pathways of the chicken may lead to new antiviral therapies. Veterinary Immunology and Immunopathology 148:1-2, 100-109. [CrossRef]

5. Matthias Liniger, Herve R Moulin, Yoshihiro Sakoda, Nicolas Ruggli, Artur Summerfield. 2012. Highly pathogenic avian influenza virus H5N1 controls type I IFN induction in chicken macrophage HD-11 cells: a polygenic trait that involves NS1 and the polymerase complex. Virology Journal 9:1, 7. [CrossRef]

6. Renfu Yin, Xinxin Liu, Chang Liu, Zhuang Ding, Xiaodong Zhang, Furong Tian, Weihong Liu, Jinghai Yu, Lin Li, Martin Hrabé de Angelis, Tobias Stoeger. 2011. Systematic selection of housekeeping genes for gene expression normalization in chicken embryo fibroblasts infected with Newcastle disease virus. Biochemical and Biophysical Research Communications . [CrossRef]

7. Ming Xu, Huanmin Zhang, Lucy Lee, Hongwei Gao, Shayan Sharif, Robert F. Silva, Mohammad Heidari. 2011. Gene Expression Profiling in rMd5- and rMd5 $\Delta$ meq-Infected Chickens. Avian Diseases 55:3, 358-367. [CrossRef]

8. Daniela Kugel, Julia Elisabeth Pulverer, Mario Köster, Hansjörg Hauser, Peter Staeheli. 2011. Novel Nonviral Bioassays for Mouse Type I and Type III Interferon. Journal of Interferon \& Cytokine Research 31:4, 345-349. [Abstract] [Full Text HTML] [Full Text PDF] [Full Text PDF with Links]

9. Mirta Balenović, Vladimir Savić, Anamaria Ekert Kabalin, Luka Jurinović, William L. Ragland. 2011. Abundance of $<\mathrm{i}>\mathrm{IFN}-\alpha<\mathrm{i}>$ and $<\mathrm{i}>\mathrm{IFN}-\gamma<\mathrm{i}>$ gene transcripts and absence of $<\mathrm{i}>\mathrm{IL}-2<\mathrm{i}>$ transcripts in the blood of chickens vaccinated with live or inactivated NDV. Acta Veterinaria Hungarica 59:1, 141-148. [CrossRef]

10. M. R. W. Barber, J. R. Aldridge, R. G. Webster, K. E. Magor. 2010. Association of RIG-I with innate immunity of ducks to influenza. Proceedings of the National Academy of Sciences 107:13, 5913-5918. [CrossRef]

11. Mohammad Heidari, Huanmin M. Zhang, Shayan Sharif. 2008. Marek's Disease Virus Induces Th-2 Activity During Cytolytic Infection. Viral Immunology 21:2, 203-214. [Abstract] [Full Text PDF] [Full Text PDF with Links]

12. Heike Schwarz, Kirsten Schneider, Annette Ohnemus, Miha Lavric, Sonja Kothlow, Stefan Bauer, Bernd Kaspers, Peter Staeheli. 2007. Chicken Toll-like Receptor 3 Recognizes Its Cognate Ligand When Ectopically Expressed in Human Cells. Journal of Interferon \& Cytokine Research 27:2, 97-102. [Abstract] [Full Text PDF] [Full Text PDF with Links] 